\title{
General And Special Education Teachers' Knowledge And Self-Efficacy Regarding Autism
}

\author{
Dr. Aeshah M Alshehri
}

Assistant Professor at Special Education Department, Education College Taibah University, KSA

\section{Abstract:}

$2 \begin{aligned} & \text { ecognition for the increased Autism Spectrum } \\ & \text { Disorder (ASD) in Saudi Arabia has increased in } \\ & \text { recent times. The need to detect Autism and }\end{aligned}$ identify the self-efficacy level among instructors forms the foundation of this study. The presence of advanced technology in diagnosis has contributed to increased cases of ASD among individuals in Saudi Arabia. Thus, teachers must have vast knowledge about ASD to assist them in addressing the needs of students. Howbeit there is a lacks of previous studies on Autism, making the information available scarce. The current study seeks to assess the prevalence of ASD, selfefficacy, and the degree of teachers' consciousness about Autism in Saudi Arabia. Again, the study assesses the intervention practices that teachers employ in Saudi Arabia to help students with ASD under the supervision of the Ministry of Education. The researchers collected data using two research instruments, namely survey, and questionnaire. The study findings found that the average number of instructors possessed modest knowledge about Autism. It also revealed a considerable gap between teachers and the general public knowledge about the prevalence of Autism in Saudi Arabia. The study findings indicated that most Autistic cases went unnoticed because teachers could not detect the symptoms. Additionally, the study showed that training instructors on general Autism to help them address the numerous cases among the learners comes in handy. In the final analysis, the study proposes that online courses conform to Saudi culture and language in enhancing teachers' selfefficacy and knowledge about Autism.

Keywords: Autism, Saudi Arabia, self-efficacy, Teachers.

\section{Introduction}

This piece of research gives background information on a recent study on Saudi Arabia teachers' knowledge of 
autism and autism self-efficacy. No research to the researcher's best knowledge, has established the connection between the knowledge of autism and selfefficacy, as discussed in the current study, of candidate educators with Autism since August 2017.

\section{The Study's Purpose}

This study aimed to detect and compare Autism and selfefficacy levels among regular and specialized learning instructors in Saudi Arabia. The study looked at these aspects to find out if autism awareness and demographics are interrelated and if there is a relation between autism self-efficacy and the demographics of teachers. Gender, teaching, education, and training programs included demographic statistics.

\section{Rationale}

In recent decades, the recognized frequency of this disease has grown significantly. In 2012, Autism affected one youngster out of every 68 in the USA (Christensen et al., 2016). Higher knowledge of diagnosis is mainly responsible for the increase, although intellectual impairments have decreased. Communities, administrations schools, families, and students may benefit from a greater awareness of self-efficacy regarding Autism.

\section{Major Research Concerns}

- What is the prevalence of Autism among Saudi Arabia's special educators?

- What is the degree of autism consciousness among Saudi Arabian regular and special education teachers? 


\section{Sub-Questions}

- Is there a link between teachers' autism consciousness and their degree of autism knowledge?

\section{The Study's Importance}

In this research, no prior study, to the researcher's best knowledge, examined the level of autistic expertise and Autism between general and specialist educational instructors in Saudi Arabia. Because of the rising incidence of Autism and Saudi Arabia's trend toward more inclusive education, all instructors must have a solid grasp of Autism and self-efficacy. This study provides information that can assist educators in enhancing the quality of autism education in Saudi Arabia by analyzing existing levels of these factors.

\section{Literature Review}

This research focused on Saudi Arabian instructors. It goes through the history of Saudi education policy and demonstrates how special education programs have progressed. It paves the way for future studies on teachers' autism understanding and self-efficacy. Gender segregation from elementary school through college gets incorporated into the cultural environment.

\section{Autism Diagnosis and Early Intervention}

In 2000, about one in 150 youngsters in America had autistic conditions, per the ADDM and the Centers for Disease Control (CDC). Six ADDM reports were used to obtain this figure. In 2012, 11 ADDM sources provided estimates on prevalence, with the ADDM predicting that one in every 68 US children had Autism (CDC, 2016). Greater awareness, increasing diagnosis, and increased 
instances are all potential contributors to the rise in prevalence. Because it reflects such a wide range of properties and is dependent on conduct, it is more difficult to diagnose people with Autism than to describe them (Murshid, 2011). The existing diagnostic standards are associated with factors from the Mental Disorders Diagnostic and Statistical Manual (DSM-5, 2013), where data from caregiver surveys, rating systems, and the individuals themselves are required (Alotaibi et al., 2016). Some autistic children do so well with early care that they no longer play on the spectrum of Autism when they are older. Many of the kids that run away, later on, share some similar traits.

According to Profanter (2009), ASD patients typically experience unfavorable responses from other people, including discrimination and infringement of human rights what's happening around the planet. Families that have kids with special needs are subject to negative stereotypes in Arab nations. Sometimes, like in Oman, students with special requirements tend to be kept at home and restrict their access to school and treatment (Profanter, 2009). These societal stigmas also partly lead to the absence of specialist autism awareness in Oman (Al-Farsi et al., 2011). In some situations, exceptional learning instructors, particularly those working higher, may not identify indications of Autism in kids.

\section{Autism Education}

Autistic students are the quickest group of special education students. The learning requirements of each student differ significantly from those of kids with other 
disabilities and those of other students with Autism (Hendricks, 2011). It is critical to developing excellent student-teacher interactions during the school years. Simpson (2004b) proposed four components to add in autism teacher training to educate instructors on how to interact with autistic children: (a) approaches for social interaction, communication, and adaptive abilities; (b) sensory issue strategies; (c) environmental changes and management approaches, and (d) Behavioral treatments that are helpful based on the functional evaluation.

\section{Lack of Autism Experience and Knowledge}

Although Autism is becoming more prevalent in schools, instructors still lack understanding of the disease and may even mistake it with other disorders. According to a poll done in the United States, instructors educated a similar percentage of children on both ends of the autistic spectrum (Hendricks, 2011). In addition, there is a knowledge gap in terms of autism prevalence, diagnostic features, causation, and support for people with Autism. Only $11 \%$ of instructors questioned in Oman said they had had interaction with a kid with Autism. According to AlSharbati et al. (2015), more than $60 \%$ of educators incorrectly felt that parental carelessness was the cause of Autism. Over half of those polled incorrectly stated that all children with Autism are unable to speak vocally. Teachers' lack of understanding of Autism may be partially related to their lack of experience with pupils with the disease, as these factors are important markers of relative knowledge of the disorder. 


\section{Gaining Knowledge through Experience: Experiential Learning Theory}

As the frequency of Autism rises, regular and special education instructors will have more opportunities to work with autistic children. Increased experience working with these children leads to more understanding of the condition, according to Kolb's (2014) experiential learning theory. Educators would have a more tangible experience with pupils if they followed this idea, reflecting on that experience. Such introspection is likely to provide new ideas about one's own experience, which they can use in the future. The cycle continues as more experiences are gained.

\section{Consciousness}

People's self relates to their belief in achieving the goals they set for themselves (Bandura, 1997). "The more the feeling of individual effectiveness, the higher the endurance and the chance of completing the task," writes Urdan and Pajares (2006). (p. 314). People must think that by taking part, they will be able to accomplish the intended outcome. They will not feel this way if they do not believe in their abilities, and they will be less likely to participate.

\section{Teachers' Self-Efficacy}

To be effective in a teaching setting, teachers must have confidence in their abilities to accomplish desired results (e.g., adopting a teaching method, conducting interventions, or promoting social connections). Direct experiences, emotional arousal, cultural and linguistic persuasions, physiological and emotional states, and self- 
evaluation are all used by teachers to enhance consciousness. Teachers, who are more self-assured, according to Tschannen-Moran et al. (1998), are more eager to devote themselves to their area. Different skills, experiences, and degrees of self-efficacy get required for other areas of teaching.

Teachers using this information to assess their selfefficacy on a case-by-case basis evaluate their feelings toward pupils and their strengths and flaws to establish their consciousness (Tschannen-Moran et al., 1998; Tschannen-Moran \& Hoy, 2007). The efficacy of instructors is determined by how they perceive their consciousness. On the other hand, their assessments reflect their consciousness of competence instead of their actual ability level. (Tschannen-Moran\& Hoy, 2007). Teachers are polled on their self-perceived competence when measuring consciousness (Urdan \& Pajares, 2006). Because consciousness is a competence evaluation, it is critical to pose questions that produce judgmental replies. Questions got phrased in "can do" rather than "will do" because the latter indicates purpose. When you ask instructors what they "can do" in the school, they will judge. Furthermore, because various aspects of education require different skills, experiences, and levels of consciousness, a comprehensive personality assessment is most effective. Moreover, a multidimensional accelerated and shared growth that encompasses various areas of teacher functionality is critical in providing a clearer understanding of teacher efficacy across their entire career. 


\section{Evidence-Based Practices for Autism}

The recipient of the 2002 CEC Special Education Research Award, Simpson has devoted his life to educating and researching autistic patients (Simpson, 2004b). He observed no single "correct way," but the most helpful strategy is generally interdisciplinary, dependent on individual needs, illustrating how well professionals work and use EBPs and personalized strategies to get outstanding results. Simpson (2004b) was quite pleased to witness the remarkable results produced in a coordinated fashion by a well-trained, multidisciplinary team.

\section{EBP Evolution}

In the 1990s, there began the push toward EBPs in medical practice in the US to keep doctors informed. It's a complex problem with numerous dimensions as it relates to schooling. The following aspects are necessarily utilized to carry out EBPs at schools: research results, professional judgments, data-based decision-making, and family and student consideration (National Autism Center, 2015). In the United States, the No Child Left behind Act was adopted in 2001 and mandated that all children with EBPs be schooled 111 times in the requirement (Simpson, 2005). Since 2004, schools are required to educate instructors to utilize EBPs via the Individuals with Disabilities Act (IDEA).

\section{Teachers' Knowledge of EBPs}

The American Hendricks research (2011) revealed that Saudi Arabian professors are not qualified in English-based Practices (EBPs). The study utilized instructor awareness of autism practices with Virginia skill skills. The list of 
abilities includes six areas of expertise: general information of autism, individualization and support techniques, communication, social skills, behavior, and sensory-motor development. There has been an emphasis on more EBP training in the US; although this is one-country research, many Saudis may also get considered to lack EBP skills.

\section{Importance of Autism Teacher Training on Knowledge}

Simpson (2004b) claimed that a shortage of specialists competent to collaborate with kids with the illness is the major problem confronting ASD. Teachers that are equipped with specific needs are needed to deal with pupils. At least 20,000 exceptional education instructors are not adequately certified (Simpson, 2004b). It presents a difficulty for schools attempting to recruit skilled teachers. Teacher training equips educators, in principle, to work with all pupils, including autistic kids. Research has shown that an appropriately prepared teacher is more likely to positively impact school kids (Council for Exceptional Children, 2015). Because of the specific demands of autistic pupils, it is at least required for instructors to learn about the disease (Robertson \& Singleton, 2010; Sindelar, Brownell, \& Billingsley, 2010). In their autism-based pupils, teachers discover a significant variety of cultural, linguistic, and economic students, making it harder to educate autistic youngsters.

\section{Required Teacher Training}

According to the Council for Exceptional Children (2015), Teachers who work in outstanding education must meet several standards before and during their employment. They need a bachelor's degree, a liberal arts 
background, mentorship, and a professional degree. Administrators must be prepared to take action if the conduct of educators is unlawful or damaging to the children in any manner. It all helps teachers learn about Autism and the ability to teach autistic children.

\section{Saudi Arabia's Special Education Background}

Saudi Arabia's Ministry of Education evaluates and compares its educational system to that of the United States annually. The Saudi Rules of Programs and Institutes for special education (RSEPI) got established in 2001. RSEPI offers information that promotes the quality of the country's special education, including individualized training programs (IEPs), evaluation processes, and the rights of students and families (Alquraini, 2011). For Saudi Arabia, a somewhat small nation that just developed its formal education system for less than a hundred years, this law (for example, RSEPI) is significant (Alquraini, 2011). Special services for disabled persons began with assistance for the benefits of the blind in 1958 .

\section{Saudi Arabian Autism Education}

Autism is a recognized and public educational disability in Saudi Arabia. Although there are no official data on the number of autistic pupils, the overall number of Autism and associated illnesses are believed to exceed 167,000 by researchers (Aljarallah, Alwaznah, \& Alnasari, 2007). Autism is a disease in which a person cannot develop communication and regular connections with other persons (Al-Faiz, 2006). It includes using what was learned, contact, isolation, and social awkwardness with the people. Several educators and people supported the students with 
autism movement in the early 1990s (Al-Faiz, 2006). The government took the effort to legalize the campaign some years later. Services for autistic pupils got formally launched in 1998. Based on Al-Mousa (2010), the Special Education General Secretariat established the first programs in 2000 for autistic kids to be educated in ordinary classrooms, rather than just in particular institutions for mentally disabled pupils.

\section{Teacher Preparation in Saudi Arabia}

The increasing number of special training facilities means that there are increasing populations of educators who need preparation. More than 2500 students study special education at King Saud University, the country's largest university (Hussain, 2010). Autism is an option for the university as a specialist field. For one year and a half, students must finish courses in their specialized field and undergo a full-time supervised experience. Educators who accomplished their internship throughout their university education said it was the most beneficial instrument for their classroom training. Sadly, many teachers also noted that the university lacked significant training resources. Professors desired more: internship experience, awareness programs, English Vocabulary to assist in internet research, IEP emphasis and case studies, various disability information, learning planning, and school methods. The results in this study showed that Saudi professors at the University of King Saud believed in their instructional years that they were not receiving sufficient particular autism training. 


\section{Teachers' Perspectives on Teacher Training for Autism in Saudi Arabia}

The perspective of instructors on their unique educational training has been studied by Alnahdi (2014a). In Riyadh, the capital of Saudi Arabia, the studies questioned around 600 professors from 30 colleges. The surveys showed no significant variation in viewpoints among instructors of different sexes or levels of experience; 74.5 percent stated they thought they had not been offering good courses to assist them in identifying their objectives. The determination of objectives for children with special needs is a crucial planning element, given that each student has an IEP or at least some kind of a customized plan. Preparing for a student objective might assist all to follow suit. More than $75 \%$ of teachers also believed that there was a deficiency in teacher preparation in transitional services training for disabled students, and $54 \%$ stated they were not aware of transition plans for disabled students before taking part. It shows that students with Autism require particular assistance, such as transition services, for more training for professors.

\section{Methodology}

The methodology examines the design and procedures of the study, how participants got chosen, the demographic, and the surveys. The methods used to do statistical analysis on the acquired data also get explored.

\section{Purpose}

As Autism grows, instructors have more contact with autism-presented pupils in Saudi Arabia. Therefore, all 
instructors need to recognize Autism as a condition, know how to teach Autism kids, and trust their work. The objectives of this research were to assess educators in Jeddah, Saudi Arabia, autism level knowledge and autism self-efficacy. These values got compared to identify any connections.

\section{Variables}

The study's dependent variables were Saudi Arabian teachers' knowledge of Autism and self-effective Autism. The study considered "autism knowledge" as factual autism information. It includes a general understanding of the condition, including features, diagnosis, and therapy. It also covered autism-related education practices - such as EBPs helpful in teaching Autism to pupils. The study attempted to identify the connections between Autism, Autism, and demographic variables in instructors.

\section{Setting}

The research got conducted at public schools in Jeddah, Saudi Arabia's most important city, with a more than $13 \%$ participation rate. There are numerous cultural and social traditions in the country. Jeddah alone is home to more than $13 \%$ of the country's population and has 3,976,000 people (Sawe, 2017). Most of the instructors got trained at the same universities, and there were the most particular services. Many families from neighboring towns are thus on their way or moving to Jeddah for specific services.

\section{Population}

The population comprised men and women professors who educate primary, middle, and secondary school, pupils. Saudi Arabia had special education. Schools are 
divided into women in Saudi Arabia, and men and women teach the men by women. Schools are divided by gender. The government finances education through the Education Ministry. That's how professors get employed and compensated. By 2015, Saudi Arabia had 527,000 teachers (Argaam, 2017). Research of eligible teachers in Jeddah at all grades was published by the Education department (2016) of Arabia. The number of instructors amounted to 30,802 . These instructors work for boys and girls in Jeddah in 1329 schools. Private and home school institutions exist, although this study used only teachers hired in public schools by the Ministry of Education.

\section{Sample}

In Jeddah, Saudi Arabia, the sample group consisted of around 30800 general and particular education instructors: males and females. They got selected by working in the educational district of Jeddah. The administration of the school district sent these questionnaires to its staff. These workers comprised male and female educators with different experiences, education, and teaching positions, who were currently teaching primary, secondary or middleschool pupils during the data collection.

\section{Instruments}

A survey got completed in three sections: demographics, teachers' autism self-efficacy scale, and participation in the autistic knowledge questionnaire (AKQ). Participants in autism education received questions to rate themselves. Ruble, Toland, Birdwhistell, McGrew, and Usher created the ASSET system (2013). Respondents received 30 test questions regarding teacher trust in autism education areas 
like assessment. Participants got asked to answer 30 actual/false questions by checking the "Do not Know" box if the answer was unclear.

\section{Procedures}

The institutional review board has approved this project of the University of Saint Louis (IRB). Online survey software guaranteed that participant names got omitted to anonymous survey replies. The questionnaires were sent to a professional translation agency in Saudi Arabia to ensure that the study was interpreted from English to Arabic and Arabic to English. Two multilingual professors at the University of Jeddah checked their knowledge and timing questionnaires after this firm approved the survey.

\section{Validity}

The ASSET and AKQ got employed to test teachers' trust in autism instruction. The ASSET requires that teachers measure their effectiveness on a 0-100 scale. With a grade of 0 , instructors believe they cannot perform the job; with a degree of 100 , they may be very sure of it. The questionnaire focused on information about autism diagnosis, symptoms, and treatment. The face validity of this measure got established to be $87 \%$ by the creators, with an internal consistency of 93 (Haimour \& Obaidat, 2013). The participants took the test anonymously to increase validity.

\section{Reliability}

When the study's object remains constant, an instrument's dependability becomes determined by its capacity to generate results (Leedy \& Ormrod, 2016) consistently. The ASSET got created with exceptional 
education instructors in mind, not with general education teachers. Because the participants in this study were a mix of public and special education instructors, a survey that was trustworthy for both was required. Therefore, the ASSET became modified for this investigation, and the revised version got used to conducting a reliability analysis. The modified ASSET's dependability got confirmed with reliability estimations ( 0.96), indicating a good level of reliability (Ruble et al., 2013). When utilizing Cronbach's alpha to assess the AKQ's internal logic, the device's dependability was determined to be $(0.93)$. The validity of the AKQ is unaffected because it got used in its original form (Haimour \& Obaidat, 2013). The AKQ got designed with no particular sort of teacher in mind. It contains a demographics component to accommodate various teaching jobs.

\section{Data Collection}

Educators in the Jeddah area got invited to participate in research carried out by the education department. The investigation got carried out with Qualtrics Online Survey Software. Teachers got assured they would remain anonymous in their answers. Two weeks were spent opening and completing their survey, and a reminder got issued to the participants to achieve their surveys.

\section{Data Analysis}

This research used quantitative data from a survey separated into three sections: demographics, ASSET, and AKQ. Data from these components got evaluated separately and then compared (see Table 1). 


\section{Question 1 of the Research}

1. What is the prevalence of Autism among Saudi Arabia's general and special education instructors?

The data were collected using ASSET, testing the autism knowledge level of participants on the 0 to 100 scale to address the first study question. The findings were analyzed using a descriptive design using SPSS utilizing frequency, percentage, average, and standard deviation.

Table 1: Research Questions and Test Type

\begin{tabular}{||c|c||}
\hline Research Question & Test Type \\
\hline \hline $\begin{array}{c}\text { Research Question 1 } \\
\text { among Saudi Arabia's general and } \\
\text { special education instructors? }\end{array}$ & $\begin{array}{c}\text { Descriptive Statistics } \\
\text { (frequencies, percentages, } \\
\text { mean, standard deviation) }\end{array}$ \\
\hline \hline $\begin{array}{c}\text { Research Question 2 } \\
\text { What is the degree of autism } \\
\text { consciousness among Saudi Arabian } \\
\text { regular and special education } \\
\text { teachers? }\end{array}$ & $\begin{array}{c}\text { Descriptive Statistics } \\
\text { (frequencies, percentages, } \\
\text { mean, standard deviation) }\end{array}$ \\
$\begin{array}{c}\text { Sub-Question 1 } \\
\begin{array}{c}\text { Is there a correlation between } \\
\text { teachers' level of autism knowledge } \\
\text { and their level of autism self-efficacy? }\end{array}\end{array}$ & $\begin{array}{c}\text { Descriptive Statistics } \\
\text { (difference between two } \\
\text { groups: } t \text {-test) }\end{array}$ \\
\hline \hline
\end{tabular}

\section{Research Question 2}

What is the degree of autism consciousness among Saudi Arabian regular and special education teachers?

Data got collected using the AKQ to address the second study question, a questionnaire in which participants assessed their degree of autism self-efficacy using one of 
three options ("true," "false," or "do not know"). The data got numerically coded, and descriptive statistical analysis, percentages, mean, and standard deviation supplied by SPSS. The coding for the second portion of the survey is shown in the list below. Each number indicates a survey score, with " 0 " representing " 0 percent" and " 10 " representing " 100 percent": $0=0$ percent, $1=10 \%, 2=$ $20 \%, 3=30 \%, 4=40 \%, 5=50 \%, 6=60 \%, 7=70 \%, 8=$ $80 \%, 9=90 \%$, and $10=100 \%$. A score of 0 indicates poor autism self-efficacy, 10 indicate strong autism selfefficacy, and 5 indicate a medium degree of autism selfefficacy.

\section{Sub-Question}

Is there a correlation between teachers' level of autism knowledge and their level of autism self-efficacy?

The demographic survey was used in conjunction with the knowledge and self-efficacy tests to answer the subquestions. In the demographics section, participants gave short answers to gather personal data about their type of teaching job. The researcher employed t-tests (for two groups) to analyze the demographic data against the data from the ASSET and AKQ.

\section{Study Findings}

This part describes the findings of the statistical analysis utilized in the research questions. It begins by describing the quantity and basic demographic information of the participants. Then two study topics are explored with support from tables and statistics showing teachers' autism knowledge and autism consciousness. 


\section{Preliminary Analysis}

The demographic survey and the AKQ were completed by 178 out of 372 participants, and only 286 got finished. $76 \%$ of participants were men and $24 \%$ women, according to the gender distribution of the sample. The male participant percentage was substantially above the female participant proportion. (See Table 2 and Figure 1).

Table 2: Gender Distribution

\begin{tabular}{||c||c|c|}
\hline Gender & $\mathrm{N}$ & Valid Percent \\
\hline \hline Male & 217 & 75.3 \\
\hline \hline Female & 69 & 24.0 \\
\hline \hline Sum & 286 & 99.3 \\
\hline \hline Absent & 2 & 0.7 \\
\hline \hline Total & 288 & 100.0 \\
\hline
\end{tabular}

In addition to noting their highest degree earned, teachers also reported whether they held a particular education degree. The vast majority did not hold a specific degree of education (76.4\%), with only $23 \%$ having earned such a degree (See Table 5 and Figure 4).

\begin{tabular}{|c|c|c|}
\hline Degree in SPED & $\mathrm{N}$ & Percent \\
\hline No & 220 & 76.4 \\
\hline Yes & 266 & 22.9 \\
\hline Sum & 286 & $\begin{array}{l}99.3 \\
\end{array}$ \\
\hline Absent & 2 & .7 \\
\hline Total & 288 & 100.0 \\
\hline
\end{tabular}

\section{Research Question 1}

What is the prevalence of Autism among Saudi Arabia's general and special education instructors? 
The autism knowledge of participants got assessed using the AKQ, which consisted of 30 true/false items. The overall average for both general and special education instructors was $41 \%$, indicating that all teachers correctly answered things $41 \%$ of the time. Teachers' ratings did not favor any one category of questions; scores varied considerably across the four categories. Question 25, concerning autism diagnosis, was the item that received the right answers (78 percent). Behavioral observation assists in diagnosing autism disorder.

In Table 8, the standard text indicates characteristics of Autism (13/30), underlined text indicates autism diagnosis (9/30), the italicized text indicates autism interventions (5/30), and the bold text indicates causes of Autism (3/30).

\section{Research Question 2}

What is the degree of autism consciousness among Saudi Arabian regular and special education teachers?

The ASSET included 30 questions that assessed the subjects' autistic Autism in a range of 0 to 100 . Only 178 of the 286 participants completed this test. These participants were $77.5 \%$ males and $22.5 \%$ females (See Table 9). The percentage of male respondents was significantly higher than the percentage of female respondents.

The AKQ, which comprised 30 accurate/false items, measured participants' autism knowledge. The aggregate average for all general and special education teachers was $41 \%$, meaning that all teachers answered questions 
correctly $41 \%$ of the time. Question 25 , which dealt with an autism diagnosis, had the correct responses (78 percent).

Table 8: Statistics for Correct Answers for Each Item in AKQ

\begin{tabular}{|c|c|c|c|c|c|c|}
\hline $\begin{array}{c}\text { Measures of } \\
\text { Dispersion }\end{array}$ & $\mathrm{N}$ & Scope & Minimum & Maximum & Mean & $\mathrm{SD}$ \\
\hline$\underline{\mathrm{V} 25}$ & $\underline{286}$ & $\underline{\underline{1}}$ & $\overline{\underline{\underline{0}}}$ & $\underline{\underline{1}}$ & .78 & .412 \\
\hline$\overline{\overline{V 15}}$ & $\overline{286}$ & $\overline{1}$ & $\overline{0}$ & $\overline{1}$ & $\overline{\overline{.63}}$ & .483 \\
\hline V14 & 286 & $\underline{1}$ & $\underline{\underline{0}}$ & $\underline{1}$ & .60 & .490 \\
\hline$\overline{\text { V16 }}$ & 286 & $\overline{1}$ & $\overline{\overline{0}}$ & $\overline{1}$ & .59 & $\bar{~} .493$ \\
\hline$\overline{\text { V28 }}$ & 286 & $\overline{1} 1$ & $\overline{0}$ & $\overline{1} 1$ & . 59 & ב.493 \\
\hline$\underline{\underline{\mathrm{V8}}}$ & $\underline{286}$ & $\underline{1}$ & $\overline{\overline{0} \underline{0}}$ & $\underline{1}$ & .59 & .493 \\
\hline$\overline{\text { V18 }}$ & 286 & 1 & $\overline{0}$ & 1 & .56 & .497 \\
\hline$\overline{\overline{V 21}}$ & 286 & 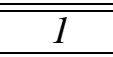 & 0 & 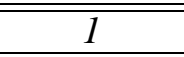 & .55 & .498 \\
\hline$\underline{\mathrm{V2}}$ & $\underline{\underline{286}}$ & $\underline{\underline{1}}$ & $\overline{\overline{0}} \underline{\underline{n}}$ & $\underline{\underline{1}}$ & $\underline{.53}$ & $\underline{.500}$ \\
\hline$\overline{V 20}$ & 286 & $\overline{1}$ & $\overline{0}$ & $\overline{1}$ & .48 & .500 \\
\hline V24 & 286 & 1 & 0 & 1 & .46 & .499 \\
\hline $\mathrm{V} 23$ & 286 & 1 & 0 & 1 & .45 & .498 \\
\hline$\overline{\text { V27 }}$ & 286 & $\mathbf{1}$ & $\overline{\mathbf{0}}$ & $\mathbf{1}$ & .44 & .498 \\
\hline V11 & 286 & 1 & $\overline{0}$ & 1 & .41 & .493 \\
\hline V7 & 286 & 1 & 0 & 1 & .36 & .481 \\
\hline 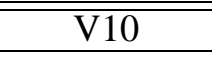 & 286 & 1 & $\overline{0}$ & $\overline{1}$ & 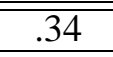 & .475 \\
\hline V9 & 286 & 1 & 0 & 1 & .33 & .471 \\
\hline$\underline{\overline{\mathrm{V} 22}}$ & 286 & $\underline{\underline{1}}$ & $\overline{\overline{0} \underline{\underline{0}}}$ & $\underline{\underline{1}}$ &. .33 & 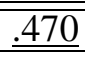 \\
\hline$\overline{2} 26$ & 286 & $\overline{1}$ & $\overline{\overline{0}}$ & $\overline{1}$ & .31 & .464 \\
\hline$\underline{\underline{\text { V13 }}}$ & $\underline{286}$ & $\underline{\underline{1}}$ & $\underline{\underline{\underline{0}}}$ & $\underline{\underline{1}}$ & .27 & .443 \\
\hline$\underline{\mathrm{V5}}$ & 286 & $\underline{\underline{1}}$ & $\underline{\overline{0}}$ & $\underline{\underline{1}}$ & .26 & .440 \\
\hline V30 & 286 & 1 & 0 & 1 & .26 & .438 \\
\hline$\overline{V 6}$ & 286 & $\overline{1}$ & $\overline{0}$ & $\overline{1}$ & .25 & .432 \\
\hline$\underline{\mathrm{V} 12}$ & 286 & $\overline{\underline{1}}$ & $\overline{\overline{0} \underline{\underline{0}}}$ & $\underline{\underline{1}}$ & .24 & ב.430 \\
\hline$\overline{\mathrm{V} 1}$ & 286 & $\overline{1} 1$ & $\overline{0}$ & $\overline{1}$ & 2.24 & (2.430 \\
\hline V17 & 286 & 1 & 0 & 1 & .24 & .428 \\
\hline V29 & 286 & 1 & $\overline{0}$ & 1 & .23 & .421 \\
\hline V19 & 286 & $\mathbf{1}$ & $\overline{\overline{0} \mathbf{0}}$ & $\overline{1}$ & .21 & $\begin{array}{l}.407 \\
\end{array}$ \\
\hline$\underline{\mathrm{V} 4}$ & $\underline{286}$ & $\underline{\underline{1}}$ & $\underline{\underline{0}}$ & $\underline{\underline{1}}$ & .20 & .404 \\
\hline$\overline{\mathrm{V} 3}$ & 286 & 1 & 0 & 1 & .09 & .292 \\
\hline $\begin{array}{c}\text { Valid N All } \\
\text { questions }\end{array}$ & 286 & & & & .41 & \\
\hline
\end{tabular}


Table 9: Gender Distribution (ASSET)

\begin{tabular}{|c|c|c||}
\hline Gender & $\mathrm{N}$ & Percent \\
\hline \hline Male & 138 & 77.5 \\
\hline \hline Female & 40 & 22.5 \\
\hline \hline Total & 178 & 100.0 \\
\hline
\end{tabular}

Table 10: Education Level (ASSET)

\begin{tabular}{|c|c||c|}
\hline Education Level & $\mathrm{N}$ & Percent \\
\hline \hline Associate's degree & 13 & 7.3 \\
\hline \hline Bachelor's degree & 120 & 67.4 \\
\hline \hline Master's degree & 41 & 23.0 \\
\hline \hline PhD & 4 & 2.2 \\
\hline \hline Total & 178 & 100.0 \\
\hline
\end{tabular}

In terms of years of experience, instructors who completed the ASSET were typical of the entire sample of teachers. For example, 52 percent of those polled had been teaching for ten years or more, compared to 54 percent polled by the AKQ. Teachers with five to ten years of experience made up $27 \%$ of the Asset group (Table 11). The others had just been teaching for a few years.

Table 11: Experience Years (ASSET)

\begin{tabular}{|c|c|c||}
\hline Years of Experience & $\mathrm{N}$ & Percent \\
\hline \hline Less than five years & 37 & 20.8 \\
\hline \hline 5-10 years & 48 & 27.0 \\
\hline \hline More than 10years & 93 & 52.2 \\
\hline \hline Total & 178 & 100.0 \\
\hline
\end{tabular}

Most teachers who completed the ASSET (75\%) did not hold a particular education degree (See Table 12), which was again similar to the percentage of teachers who did not have a specific education degree in the AKQ group (76.5\%, see Table 5). However, more participants who held a particular education degree completed the AKQ and ASSET (68\%) instead of those without a specific education degree who had completed the AKQ and ASSET (60\%). 
Table 12: Teachers with Special Education Degree (ASSET)

\begin{tabular}{|c||c|c|}
\hline Degree in SPED & N & Percent \\
\hline \hline No & 133 & 74.7 \\
\hline Yes & 45 & 25.3 \\
\hline Total & 178 & 100.0 \\
\hline
\end{tabular}

The vast majority of instructors who took the ASSET said they had no prior experience working in special education (See Table 13), which was quite close to the AKQ chosen by 66 percent of all instructors. The demographic data for the ASSET was following the demographic information for the entire sample. Only 36\% of instructors said they have worked in a unique educational setting.

Table 13: Teachers with Experience in Special Education (ASSET)

\begin{tabular}{||c||c|c|}
\hline Experience with SPED & $\mathrm{N}$ & Percent \\
\hline \hline No & 114 & 64.0 \\
\hline \hline Yes & 64 & 36.0 \\
\hline \hline Total & 178 & 100.0 \\
\hline
\end{tabular}

The majority of the teachers that finished ASSET indicated that they did not already have any particular education expertise. (See Table 13). The data was comparable to the AKQ chosen by 66 percent of all instructors. The ASSET's demographic statistics matched the entire sample's demographic data. Only $36 \%$ of instructors said they have worked with children with special needs.

Table 14: Teachers with Experience Working with Students with Autism (ASSET)

\begin{tabular}{|c|c|c|}
\hline Experience with Autism & $\mathrm{N}$ & Percent \\
\hline \hline No & 121 & 68.0 \\
\hline \hline Yes & 57 & 32.0 \\
\hline \hline Total & 178 & 100.0 \\
\hline
\end{tabular}


Table 15 shows the distribution of average scores on the ASSET for all 178 teachers who completed the ASSET.

Table 15: Statistics for Correct Answers for Each Item of the ASSET

\begin{tabular}{|c|c|c|c|c|c|c|c|}
\hline $\begin{array}{l}\text { Measures of } \\
\text { Dispersion }\end{array}$ & $\mathbf{N}$ & Scope & Minimum & Maximum & Mean & SD & Variance \\
\hline QID43_1 & 178 & $\mathbf{1 0}$ & $\overline{\mathbf{0}}$ & $\overline{10}$ & 6.15 & 3.145 & 9.892 \\
\hline "QID43_2 & $\mathbf{1 7 8}$ & $\overline{10}$ & $\overline{\overline{\mathbf{0}}}$ & $\overline{\mathbf{1 0}}$ & 6.02 & 2.938 & 8.632 \\
\hline 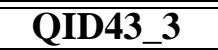 & $\mathbf{1 7 8}$ & $\overline{10}$ & $\overline{\overline{\mathbf{0}}}$ & $\overline{\mathbf{1 0}}$ & 5.83 & $\mathbf{3 . 0 3 0}$ & 9.180 \\
\hline QID43_4 & $\mathbf{1 7 8}$ & 10 & $\overline{\mathbf{0}}$ & $\overline{10}$ & 5.66 & 3.038 & 9.230 \\
\hline QQID43_5 & 178 & $\overline{10}$ & $\overline{\overline{0}}$ & $\overline{10}$ & 6.58 & 3.052 & 9.318 \\
\hline $\begin{array}{l}\text { QID43_6 } \\
\end{array}$ & 178 & $\overline{10}$ & $\overline{\overline{0} \mathbf{0}}$ & $\overline{10}$ & 6.74 & 3.202 & 10.252 \\
\hline QID43_7 & 177 & $\overline{10}$ & $\overline{0}$ & $\overline{10}$ & 7.19 & 2.864 & 8.202 \\
\hline QQID43_8 & 178 & $\overline{10}$ & $\overline{\overline{0}}$ & $\overline{10}$ & 6.62 & 3.126 & 9.773 \\
\hline "QID43_9 & $\mathbf{1 7 8}$ & $\overline{10}$ & $\overline{\overline{\mathbf{0}}}$ & $\overline{10}$ & 6.56 & 3.029 & 9.175 \\
\hline QQID43_10 & 177 & $\mathbf{1 0}$ & $\overline{\mathbf{0}}$ & $\overline{10}$ & 6.47 & 2.888 & 8.341 \\
\hline QID43_11 & 178 & $\overline{10}$ & $\overline{\mathbf{0}}$ & $\overline{10}$ & 6.64 & 2.841 & 8.073 \\
\hline QID43_12 & $\mathbf{1 7 8}$ & 10 & $\overline{\overline{\mathbf{0}}}$ & $\overline{\mathbf{1 0}}$ & 6.66 & 2.834 & $\overline{8.033}$ \\
\hline QID43_13 & 178 & $\overline{10}$ & $\overline{\mathbf{0}}$ & $\overline{10}$ & 6.15 & 2.961 & 8.770 \\
\hline 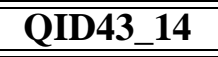 & $\mathbf{1 7 8}$ & $\overline{10}$ & $\overline{\overline{0}}$ & $\overline{10}$ & 6.32 & 3.059 & 9.360 \\
\hline QID43_15 & 178 & $\overline{10}$ & $\overline{\mathbf{0}}$ & $\overline{10}$ & 6.63 & 2.864 & 8.201 \\
\hline QID43_16 & 178 & $\overline{10}$ & $\overline{\mathbf{0}}$ & $\overline{10}$ & 6.81 & 2.896 & 8.389 \\
\hline QQID43_17 & $\mathbf{1 7 8}$ & 10 & $\overline{\mathbf{0}}$ & $\overline{10}$ & 6.58 & 2.868 & 8.223 \\
\hline QQID43_18 & 178 & 10 & $\overline{\mathbf{0}}$ & $\overline{10}$ & 6.52 & 2.956 & 8.737 \\
\hline 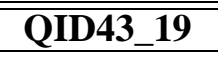 & $\mathbf{1 7 8}$ & $\overline{\mathbf{1 0}}$ & $\overline{\overline{\mathbf{0}}}$ & $\overline{\mathbf{1 0}}$ & 6.58 & 2.877 & 8.278 \\
\hline QID43_20 & $\mathbf{1 7 8}$ & 10 & $\mathbf{0}$ & 10 & 6.34 & 3.016 & 9.095 \\
\hline QQID43_21 & $\mathbf{1 7 8}$ & 10 & $\overline{\mathbf{0}}$ & $\overline{10}$ & 6.49 & 2.902 & 8.421 \\
\hline QQID43_22 & $\mathbf{1 7 8}$ & $\overline{\mathbf{1 0}}$ & $\overline{\overline{\mathbf{0}}}$ & $\overline{\mathbf{1 0}}$ & 6.58 & 2.822 & $\overline{\overline{7} 7.963}$ \\
\hline QQID43_23 & 177 & 10 & $\overline{\mathbf{0}}$ & 10 & 6.54 & 2.792 & 7.796 \\
\hline QQID43_24 & $\mathbf{1 7 8}$ & 10 & $\overline{\mathbf{0}}$ & $\overline{\mathbf{1 0}}$ & 7.52 & 2.797 & 7.822 \\
\hline QID43_25 & 178 & 10 & $\mathbf{0}$ & 10 & 6.97 & 2.849 & 8.118 \\
\hline QID43_26 & 178 & $\overline{\mathbf{1 0}}$ & $\overline{\mathbf{0}}$ & $\overline{\mathbf{1 0}}$ & 6.99 & 2.610 & 6.813 \\
\hline 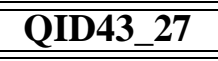 & 178 & $\overline{10}$ & $\overline{\mathbf{0}}$ & $\overline{10}$ & 5.90 & 2.955 & $\begin{array}{l}8.731 \\
\end{array}$ \\
\hline QID43_28 & 178 & 10 & $\mathbf{0}$ & 10 & 7.26 & 2.938 & 8.633 \\
\hline 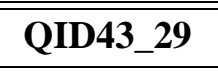 & 178 & 10 & $\overline{\mathbf{0}}$ & 10 & $\begin{array}{l}7.37 \\
\end{array}$ & 2.867 & 8.222 \\
\hline QID43_30 & 178 & 10 & $\mathbf{0}$ & 10 & 6.12 & 3.027 & 9.160 \\
\hline
\end{tabular}


The average ASSET score for teachers was 6.56 out of 100 , down from 65.6 out of 100 previously, indicating that instructors have a comparable degree of autistic selfefficiency across diverse settings. Overall, the findings revealed that general and special education instructors had autism self-efficacy to a modest degree.

\section{The Sub-Question}

Sub-Question 1 asked, "Is there a correlation between teachers' level of autism knowledge and their level of autism self-efficacy?" Using the AKQ and ASSET scores, teachers' levels of autism knowledge and self-efficacy got examined to see if there was a link. (See Table 16 and Figure 7). The substantial standard deviation revealed that instructors' results varied widely, with some far outperforming the mean.

Table 16: Mean Percentile for AKQ and ASSET Scores

\begin{tabular}{|c|c|c|c|}
\hline $\begin{array}{c}\text { Descriptive } \\
\text { Statistics }\end{array}$ & & & \\
\hline Test & Mean & SD & $\mathrm{N}$ \\
\hline AKQ & 12.3315 & 5.21918 & 178 \\
\hline ASSET & 6.5594 & 2.28036 & 178 \\
\hline
\end{tabular}

According to the Pearson correlation test, there was a link between these two variables: the higher the amount of autism knowledge among instructors, the higher their level of Autism self-efficacy (See Table 17 and Figure 7). At level 0.01, the association between AKQ and ASSET was modest $(\mathrm{r}=.310)$ but significant $(\mathrm{p}=.000)$. The bulk of the individuals had autism knowledge scores in the moderate to high range. It is worth mentioning that having more knowledge was connected to having more consciousness. 


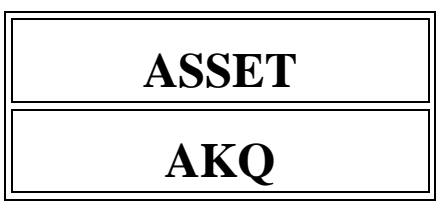

Figure7: Correlation between the AKQ and ASSET Table 17: Correlation between the AKQ and ASSET

\begin{tabular}{||c||c|c|c||}
\hline \multicolumn{1}{|c||}{ Correlations } & \multicolumn{2}{|c|}{} \\
\hline \hline Test & & AKQ & ASSET \\
\hline AKQ & Pearson Correlation & 1 & $.310^{*}$ \\
\hline Sig. (2-tailed) & & .000 & \\
\hline \hline ASSET & Pearson Correlation & $.310^{*}$ & 1 \\
\hline \hline Sig. (2-tailed) & .000 & & \\
\hline
\end{tabular}

Note. *Correlation significant at 0.01 (2-tailed). b. Listwise $N=178$.

\section{Discussion and Conclusion}

\section{Overview of Study}

This research aimed to see how well Saudi Arabian general and exceptional education instructors understood Autism and how confident they served autistic students. In assessing participants' autism knowledge, the AKQ employed a series of 30 true/false questions organized into four categories: autism features, autism diagnosis, autism therapy, and autism causes. Instructors who had taken a particular education course earned an average score of 8.05, while those who had not received an exceptional education degree received a 7.39. Only 178 of the 286 people who took the ASSET rated their confidence in autism teaching scenarios.

\section{Conclusions}

\section{Number of Participants}

The number of people who completed both the AKQ and the ASSET was lower than those who only completed the 
AKQ $(\mathrm{N}=286)$, which might be because both surveys and the demographic survey take longer to complete. The majority of those with an exceptional education degree completed all of the questionnaires (45 out of 66). Instructors in special education may have been more involved in autism research than teachers in regular education.

\section{Teachers' Autism Knowledge}

When Autism is a subject, the results reveal that regular and special education instructors have a modest degree of comprehension in Saudi Arabia, with teachers answering AKQ questions correctly 41 percent of the time. Although the 286 AKQ respondents did not favor categories when answering questions, several items stood out. Question 19 was fascinating as only $21 \%$ of teachers answered it correctly. In the autism causes class, it states that "poor parenting practices can cause autism." Teachers scored comparatively high on the other two items in the cause category.

This finding became reflected in past research in Saudi Arabia. Alqahtani's (2012) interviews suggested that some Saudi parents, especially mothers, felt guilty believing that they caused their children's Autism by being distant, not showing emotion, or not giving their children enough attention. According to a survey conducted by Al-Sharbati et al. (2015), over $60 \%$ of educators feel irresponsible parents blame Autism. This belief was made famous by Kanner in the 1960s (National Autism Center, 2015). Since the 1990s, however, research has indicated that this is not the case (Dissanayake \& Crossley, 1996), 
and in the US, there is now an understanding that parenting practices do not cause Autism (Whaley, 2002). It is clear from the current study results that more education is needed in Saudi Arabia to reverse some educators' beliefs about this topic.

These findings align with previous studies that found a gap in knowledge among teachers and the general public. People have shown a lack of autism knowledge regarding autism prevalence, diagnostic characteristics, etiology, and support to give those with Autism (Alqahtani, 2012; Dillenburger et al., 2013; Gillespie-Lynch et al., 2015; Imran et al., 2011). Exceptional education instructors have even been unable to detect autistic signs in kids who are considerably better functioning. In some cases, students do not receive the proper diagnosis in school because their symptoms go unrecognized (Zeina et al., 2014). It might be due to a mismatch between the type of behavior and the diagnostic criteria proposed in the current investigation.

\section{Teachers' Autism Self-Efficacy}

The stronger their autistic self-efficacy, the more autism knowledge instructors exhibited. The average ASSET score for all teachers was 6.56 out of ten (from 65.6 out of 100 ), indicating that both teachers in regular and particularly unique education were mildly autistic. These tests got used to establish their consciousness of expertise rather than determine their absolute skill level (TschannenMoran \& Hoy, 2007). On the other hand, Bandura (1977) claimed conscience to be a significant predictor of actual conduct. According to these results, teachers rated their 
self-efficacy the lowest in situations where they would be required to analyze behavioral and assessment data to create interventions, teaching goals, and objectives for the student. These findings are consistent with Alnahdi (2014a), where $74.5 \%$ of Riyadh's special education teachers said they did not receive courses to help determine students' goals. Participants in the current study also rated their self-efficacy low in situations where they must sustain a student's attention, a critical part of educating a student with Autism.

\section{Limitations}

The study evaluating teachers' autism knowledge and self-efficacy found correlations between factors rather than causation. It did not try to figure out why instructors have varying levels of awareness of Autism or why regular and special education teachers perform differently. The sample was chosen from only one city with no chance for instructors in other locations to reply. Inaccurate interpretations based on language and cultures were an issue. Regardless of these limitations, research in this field is rare in Saudi Arabia, and further inquiry is needed to continue particular education reform.

\section{Implications and Recommendations}

Teachers' self-efficacy increased as their autism understanding increased. Teachers with better self-esteem are more ready to devote themselves to their area. (Tschannen-Moran et al, .1998). Higher autism knowledge was associated with a particular education degree, a higher degree, and being a new teacher or having many years of experience. These traits were not associated with a stronger 
feeling of autism self-efficacy. Having more experience, on the other hand, was not adequate to improve the link between autism consciousness and autism expertise, according to the current study.

Most teachers in the current study, even those who had received training, reported low autism self-efficacy when considering situations where they would be assessing, working on behavior interventions, altering curriculum, or holding a student's attention. This finding suggested a need for training that focuses on general autism knowledge and training that deals with more extensive practices in autism education. Before teachers even enter the workforce, they should have completed extensive training in their university programs, especially earning unique education degrees. With government-supported general education in Saudi Arabia, the government should develop additional measures to promote the formation of Autism. Of course, this is an initiative that will take time to implement. Increased awareness about the disorder and education issues could also help push new policies forward.

Research shows that professors need to do up-to-date EBP training to enhance their competence, autism understanding, and capacity to utilize EBPs. (e.g., Morrier et al., 2011; Suhrheinrich, 2011). One option, especially for schools with limited time and resources, is to offer web-based training for teachers. This option may also facilitate equal education for men and women since participants could engage in the courses in the privacy of their own homes and schools. A brief online training 
course on Autism can enhance autism understanding by focusing on nature, the nature of Autism, communication, and social development (Gillespie-Lynch et al., 2015; Rakap et al., 2015). These web-based courses get modified carefully to match Saudi Arabia's culture and language. Along with a move toward more autism-specific training to enhance teachers' autism knowledge and self-efficacy, further research on the effects of autism knowledge and self-efficacy in the classroom must be conducted. With more understanding of how these variables affect teaching practices in Saudi classrooms, more specific training needs to get developed in general and special education.

\section{Summary}

The conclusion provided a summary of the study and its significant results. This study intended to identify the consciousness and expertise of Autism in Saudi Arabia among teachers of general and special education. The results showed that further research in the field of selfefficacy teacher training is needed. Finally, the study revealed practical implications and recommendations for improving teaching techniques for autistic children in regular education environments.

\section{Conclusion}

The study showed that Saudi Arabia has average to low levels of autism knowledge and a moderately high level of autistic autism self-efficacy among general and special education instructors. Autism is proven to be associated with Autism and consciousness. It is discovered that the more self-effectiveness autism instructors possessed conceptual understanding and specialized education. 


\section{References}

- Al-Farsi, Y. M., Al-Sharbati, M. M., Al-Farsi, O. A., Al-Shafaee, M. S., Brooks, D. R., \& Waly, M. I. (2011). Brief report: Prevalence of autistic spectrum disorders in the Sultanate of Oman. Journal of Autism and Developmental Disorders, 41(6), 821-825.

- Al-Faiz, H. S. (2006). Attitudes of elementary school teachers in Riyadh, Saudi Arabia toward the inclusion of children with Autism in public education (Doctoral dissertation). Retrieved from ProQuest Dissertations and Theses database. (Accession Order No. AAT 3262967)

- Aljarallah, A., Alwaznah, T., \& Alnasari, S. (2007). A study of autism and developmental disorders in Saudi children. King Abdulaziz City for Science and Technology, Kingdom of Saudi Arabia.

- Al-Mousa, N. A. (2010). The experience of the Kingdom of Saudi Arabia in mainstreaming students with special educational needs in public schools: A success story. Riyadh, Saudi Arabia: The Arab Bureau of Education for the Gulf States.

- Alnahdi, G. (2014a). Special education programs for students with intellectual disability in Saudi Arabia: Issues and recommendations. Journal of the Association of Special Education, 15(1), 83-91.

- Alotaibi, F., Dimitriadi, Y., \& Kempe, A. (2016). Perceptions of teachers using social stories for children with autism at special schools in Saudi Arabia. Journal of Education and Practice, 7(11), 85-97.

- Alqahtani, M. M. (2012). Understanding autism in Saudi Arabia: A qualitative analysis of the community and cultural context. Journal of Pediatric Neurology, 10(1), 15-22. doi:10.3233/JPN2012-0527

- Alquraini, T. (2011). Special education in Saudi Arabia: Challenges, perspectives, future, possibilities. International Journal of Special Education, 26(2), 149-159.

- Al-Sharbati, M. M., Al-Farsi, Y. M., Ouhtit, A., Waly, M. I., AlShafaee, M., Al-Farsi, O., ... \& Al-Adawi, S. (2015). Awareness about Autism among school teachers in Oman: A cross-sectional study. Autism: The International Journal of Research and Practice, 19(1), 6-13. doi:10.1177/1362361313508025 
- Argaam. (2017). [New academic year statistics]. Retrieved from http://gulf.argaam.com/article/articledetail/533051

- Bandura, A. (1977). Self-efficacy: Toward a unifying theory of behavioral change. Psychological Review, 84(2), 191-215.

- Bandura, A. (1997). Self-efficacy: The exercise of control. New York: Freeman.

- Council for Exceptional Children. (2015). What every special educator must know: Professional ethics \&standards (7th ed.). Arlington, VA: Council for Exceptional Children.

- Diagnostic and Statistical Manual (DSM-5). (2013). Dillenburger, K., Jordan, J. A., McKerr, L., Devine, P., \& Keenan, M. (2013). Awareness and knowledge of autism and autism interventions: A general population survey. Research in Autism Spectrum Disorders, 7, 1558-1567. doi:10.1016/j.rasd.2013.09.004

- Dissanayake, C., \& Crossley, S. A. (1996). Proximity and social behaviors in Autism: Evidence for attachment. Journal of Child Psychology and Psychiatry, and Allied Disciplines, 37, 149-156. doi:10.1111/j.1469-7610.1996.tb01386.x

- Gillespie-Lynch, K., Brooks, P. J., Some, F., Obeid, R., ShaneSimpson, C., Kapp, S. K., ... Smith, D. S. (2015). Changing college students' conceptions of Autism: An online training to increase knowledge and decrease stigma. Journal of Autism and Developmental Disorders,45(8),2553-2566. doi:10.1007/ s10803015-2422-9

- Haimour, A. I., \& Obaidat, Y. F. (2013). School teachers' knowledge about Autism in Saudi Arabia. World Journal of Education, 3(5), 45-56.

- Hendricks, D. (2011). Special education teachers serving students with Autism: A descriptive study of the characteristics and selfreported knowledge and practices employed. Journal of Vocational Rehabilitation, 35(1), 37-50.

- Hussain, O. (2010). Evaluation of preparation program for teachers specializing in learning disabilities in Saudi Arabia (Unpublished doctoral dissertation). University of New Mexico, Albuquerque, New Mexico.

- Imran, N., Chaudry, M. R., Azeem, M. W., Bhatti, M. R., Choudhary, Z. I., \& Cheema, M. A. (2011). A survey of autism knowledge and attitudes among the healthcare professionals in Lahore, Pakistan. BMC Pediatrics, 11(1), 107-113. 
- Kolb, D. A. (2014). Experiential learning: Experience as the source of learning and development. Englewood Cliffs, NJ: FT Press.

- Leedy, P., \& Ormrod, J. (2016). Practical research: Planning and design. Upper Saddle River, NJ: Pearson.

- Ministry of Education. (2016).[Kingdom of Saudi Arabia]. Retrieved from https://www.moe.gov.sa/ar/Pages/ Statistical Information. aspx

- Morrier, M. J., Hess, K. L., \& Heflin, L. J. (2011). Teacher training for implementation of teaching strategies for students with autism spectrum disorders. Teacher Education and Special Education, 34(2), 119-132.

- Murshid, E. Z. (2011). Characteristics and dental experiences of autistic children in Saudi Arabia: Cross-sectional

- Diagnostic and Statistical Manual (DSM-5). (2013).

- National Autism Center. (2015). Evidence-based practice and Autism in the schools (2nd ed.). Randolph, MA: National Autism Center. No Child Left Behind Act of 2001, PL 107-110, 20 USC § 6319 (2002).

- characteristics influencing intervention choices in autism spectrum disorders. Focus on Autism and Other Developmental Disabilities 28(3), 138-146.

- Profanter, A. (2009). Facing the challenges of children and youth with special abilities and needs on the fringes of Omani society. Children and Youth Services Review, 31(1), 8-15.

- Rakap, S., Jones, H. A., \& Emery, A. K. (2015). Evaluation of a web-based professional development program (Project ACE) for teachers of children with autism spectrum disorders. Teacher Education and Special Education, 38(3), 221-239. doi:10.1177/ 0888406414535821

- Robertson, J. S., \& Singleton, J. D. (2010). Comparison of traditional versus alternative preparation of special education teachers. Teacher Education and Special Education,33, 213-224. doi:10.1177/0888406409359904

- Ruble, L. A., Toland, M. D., Birdwhistell, J. L., McGrew, J. H., \& Usher, E. L. (2013). Preliminary study of the autism self-efficacy scale for teachers (ASSET). Research in Autism Spectrum Disorders, 7(9), 1151-1159. 
- Sawe, B. E. (2017). Biggest cities in Saudi Arabia. Retrieved from http://www.worldatlas.com/articles/biggest-cities-in-Saudiarabia.html

- Simpson, R. L. (2004b). Finding effective intervention and personnel preparation practices for students with autism spectrum disorders. Exceptional Children, 70(2), 135-144.

- Simpson, R. L. (2005). Evidence-based practices and students with autism spectrum disorders. Focus on Autism and Other Developmental Disabilities, 20(3), 140-149.

- Sindelar, P. T., Brownell, M. T., \& Billingsley, B. (2010). Special education teacher education research: Current status and future directions. Teacher Education and Special Education, 33, 8-24. doi:10.1177/0888406409358593

- Suhrheinrich, J. (2011). Training teachers to use pivotal response training with children with Autism: Coaching as a critical component. Teacher Education and Special Education, 34(4), 339-349.

- Tschannen-Moran, M., \& Hoy, A. W. (2007). The differential antecedents of self-efficacy beliefs of novice and experienced teachers. Teaching and Teacher Education,23(6), 944-956. doi:10.1016/j.tate.2006.05.003

- Tschannen-Moran, M., Hoy, A. W., \& Hoy, W. K. (1998). Teacher efficacy: Its meaning and measure. Review of Educational Research,68(2), 202-248. doi:10.2307/1170754

- Urdan, T. C., \& Pajares, F. (2006). Self-efficacy beliefs of adolescents. Greenwich, CT: Information Age.

- Whaley, C. H. (2002). Special education teachers and speech therapists' knowledge of autism spectrum disorder. Retrieved from Electronic theses and dissertations. (Paper 717)

- Zeina, R. M., Al-Ayadhi, L., \& Bashir, S. (2014). Autism spectrum disorder: Main problem waiting for solution in Kingdom of Saudi Arabia. Autism, 8(8), 487-490.

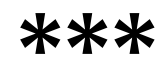

